\title{
Simbolisme Katak dalam Upacara Meminta Hujan Babangkongan di Desa Surawangi Kabupaten Majalengka
}

\author{
Lina Marliana Hidayat \\ Program Studi Tari Fakultas Seni Pertunjukan \\ Institut Seni Budaya Indonesia Bandung \\ Jalan Buahbatu No 212 Bandung \\ Email: linamarlianahidayat@gmail.com
}

\begin{abstract}
Babangkongan Ceremony is performed by the farmers of Surawangi village, in the Jatiwangi districts of Majalengka regency, during halodo season (long summer), in times of drought. The Surawangi villagers believe that performing Babangkongan Ceremony will invoke rain and provide enough water for their crops. This research implements a qualitative approach with Mircea Eliade's symbolism theory emphasizing on existential symbolism. In particular, the theory proposes that every symbol refers to human condition and the necessity to nourish its connection to the source of life that circumscribes it. When water is scarce, Babangkongan is the villagers' way to ensure rainfall for their fields. The ceremony starts at nighttime in the Kuwu's (chief of village) house. It opens with the ritual of group prayers led by a kokolot (village elder). Then, an actor playing the role of Bangkong (the Toad), half-naked with only a pair of shorts, will be set to ride a palanquin carried by several men around the village. The palanquin then must travel around the village in an anti-clockwise route normally called Ider Naga. During the round, the bearers of the palanquin must each mimic the sound of the toads in a reciprocal way, while making periodic stops in front of villagers' houses who have been waiting for them. The villagers will proceed to splash water from buckets or other vessels onto the actor playing Bangkong. The ritual ends when the palanquin has made its way back to its departure spot. Afterwards, a closing ceremony will be held at the same Kuwu's house. Right at midnight, the entire Babangkongan proceeding is concluded. To note, the mimicking of toad sounds and the toad impersonation serve as a symbolism for toads, the animals that are closely associated with rain and the fertility of rice paddies.
\end{abstract}

Keywords: Babangkongan, toad, toad symbolism

\begin{abstract}
ABSTRAK
Upacara Babangkongan dilaksanakan masyarakat Desa Surawangi Kabupaten Majalengka pada musim halodo (hujan tidak turun-turun). Masyarakat desa Surawangi percaya bahwa dengan melaksanakan upacara Babangkongan, hujan akan turun. Penelitian ini menggunakan metode kualitatif dengan pendekatan teori simbolisme dari Mircea Eliade yang menekankan nilai eksistensial simbolisme, di mana simbol selalu mengarahkan pada suatu situasi manusia terlibat di dalamnya, juga selalu menjaga hubungan dengan sumber kehidupan yang melingkunginya. Ketika sawah kekurangan air, mereka melakukan upacara meminta hujan Babangkongan. Upacara dilakukan malam hari dari rumah Kuwu (kepala desa). Diawali dengan upacara berdoa bersama yang dipimpin seorang kokolot (tetua desa), kemudian aktor yang berperan sebagai Bangkong (katak) menaiki usungan lalu diarak keliling Desa mengambil alur melawan arah jarum jam yang disebut Ider Naga. Pada saat keliling itu para pengusung menirukan suara katak yang bersahut-sahutan, beberapa penduduk sudah menunggu arakarakan sambil mengguyurkan air dari ember dan wadah lainnya kepada aktor yang berperan sebagai Bangkong. Upacara Babangkongan berakhir kembali ketitik berangkat di rumah Kuwu (kepala desa). Kemudian di adakan upacara penutup, upacara Babangkongan selesai. Peniruan suara katak dan penghadiran aktor yang berperan sebagai katak merupakan bentuk simbolisme Katak yang erat hubungannya dengan mendatangkan hujan.

Hujan untuk kesuburan sawah.
\end{abstract}

Kata kunci: Babangkongan, katak, simbolisme katak 


\section{PENDAHULUAN}

Upacara meminta hujan, memiliki ragam bentuk disetiap daerah di Indonesia. Terutama pada masyarakat agraris. Pesawahan sebagai lahan warisan turun temurun, keberlangsungan kesuburannya perlu terus dijaga dan dipelihara. Pesawahan yang terjaga dan terpelihara akan mendatangkan panenan yang menggembirakan para pemiliknya. Bentuk penjagaan dan pemeliharaan pesawahan kalau terjadi halodo (hujan tidak turun turun), dilakukan upacara ritual yang dipercaya memiliki kemanjuran (efficasy) yaitu upacara meminta hujan. Salah satu kepercayaan yang sudah menjadi tradisi turun temurun adalah upacara meminta hujan. Sebagai contoh terdapat dua upacara meminta hujan yang berbeda karakternya di dua daerah. Pertama adalah di daerah Madura, yaitu upacara Dhâmmong, di mana gambarannya sebagai berikut:

"Sebuah Musik Katak Pemanggil Hujan. Malam itu, sekitar pukul 20.00 WIB, di perempatan jalan Desa Palasa Talango, dekat Buju' Kramat, beberapa warga desa berkumpul. Mereka duduk bersila dengan posisi agak melingkar. Tidak ada lampu penerang sehingga wajah mereka satu persatu agak sulit dikenali. Kepulan asap rokok keluar dari mulutnya sebagai pengusir hawa dingin yang mulai menusuk kulitnya. Untuk mengusir rasa jenuh menunggu sebagian warga lainnya, sesekali terdengar gurauan di antara mereka. Beberapa saat kemudian, muncul seorang tua berpakaian baju putih, sarung kotak-kotak berwarna agak gelap dipadu dengan songkok hitam seperti kebanyakan warga lainnya. Rupanya ia adalah Kyai Mushlihin, seorang ustad di desa itu. Sontak puluhan orang itu pun bangkit secara serempak dari tempat duduknya masing-masing bak disengat listrik untuk memberi hormat. Dengan tertib dan antri satupersatu, mereka menyalami tangan sang ustad. Suasana menjadi hening hingga mereka kembali ke tempat duduknya semula. Sang ustad lalu memecah kesunyian dengan melantunkan pantun yang dilagukan. Dalam ritual tersebut, mereka memainkan musik mulut yang diadaptasi dari berbagai suara binatang, seperti burung gagak, ayam, anak ayam, burung, katak, dan sebagainya yang diaransemen sedemikian rupa sehingga menghasilkan paduan musik yang syahdu. Mereka, kemudian, memadukannya dengan pantun-pantun (paparéghân) Madura. Dhâmmong itu sendiri berarti pujian (pojiân) atau permohonan yang disertai 'ancaman', seperti seorang ibu yang menggendong anaknya sembari melantunkan lagu-lagu pujian disertai ancaman agar anaknya cepat tidur." (Hefni, 2008, hlm. 66-67).

Menyimak kutipan tersebut, nampak bahwa upacara memanggil hujan terdapat juga di Madura. Hanya sudah berakulturasi dengan budaya Islam, sebagaimana salah satu khas masyarakat Madura yang Islami. Selain itu upacara meminta hujan terdapat juga di daerah Jawa Barat, tepatnya di Desa Luragung Landeuh Kecamatan Luragung Kabupaten Kuningan Jawa Barat. Penulis pernah menelitinya, dan artikelnya sudah dimuat di Jurnal Ekspresi Seni, volume 17, No 2, November 2015 (Hidayat, 2015, hlm. 242):

"Sejalan dengan pemikiran Victor Turner dalam buku From Ritual To Theatre, dalam Bab Ritual DramaticDrama Ritual mengatakan bahwa pertunjukan seperti itu dapat dikatakan sebagai sebuah proses yang terjadi di masyarakat di dalam bentuk variasivariasi pertunjukan yang berkembang 
beberapa genre seperti halnya ritual, perayaan, carnaval, festival, permainan, tontonan, parade, dan peristiwa olah raga. Di mana secara khusus untuk Cingcowong dapat dikatagorikan sebagai upacara masyarakat di dalam mewujudkan aktivitas percobaan dan pemahaman serta perubahan dari sebuah ritual peminta hujan menjadi sebuah pertunjukan sebagaimana dikatakan lebih jauh lagi olerh Victor Turner hal ini disebut dialektika antara mengalir dan refleksi karakteristik bentuk genre dari sebuah ritual ke pertunjukan di dalam satu transendensi yang memiliki bentuk berlawanan antara spontanitas dan bentuk aksi kesadaraan diri." (Turner, 1982, hlm. 25).

Kembali pada upacara Babangkongan, ternyata dua contoh upacara tersebut (Dhâmmong dan Cingcowong) tujuannya sama meminta hujan, tetapi cara penyajian dan peristiwanya berbeda. Sesungguhnya masih banyak upacara meminta hujan di pelbagai daerah di Indonesa, sebagai potensi kelokalan yang perlu terus digali dan diteliti.

\section{METODE}

Penelitian tentang Babangkongan, telah dilakukan sejak tahun 2014, sampai dengan 2019, dan berlanjut tahun 2020 dengan fokus perhatian pada simbolisme katak. Adapun metode yang dipakai adalah metode kualitatif, di mana penulis melakukan observasi dan pengolahan data lapangan serta studi pustaka yang dianggap mendukung. Penelitian kualitatif pada umumnya dilakukan dengan pertimbangan bahwa penelitian tersebut haruslah eksploratif (Creswell, 2012, hlm. 41). Eksplorasi yang dimaksud adalah terus menerus membuka peluang untuk diteliti, secara bertahap. Sebagaimana yang penulis lakukan.

Upacara Babangkongan di Desa Surawangi Kecamatan Jatiwangi Kabupaten Majalengka menginjak tahun 2014 telah diteliti oleh Tim peneliti, antara lain: penulis, Dindin Rasidin, dan Yayat Hidayat. Penelitian tersebut mendiskripsikan upacara Babangkongan berdasarkan pandangan-pandangan emik pelakunya. Kemudian melakukan pendokumentasian upacara Babangkongan, baik foto maupun film. Kemudian pada tahun 2019, kembali penulis terlibat dalam program Pengabdian Kepada Masyarakat (PKM) bersama Yayat Hidayat, hasilnya adalah Pengemasan Upacara Babangkongan menjadi Seni Pertunjukan Babangkongan di Desa Surawangi Kecamatan Jatiwangi Kabupaten Majalengka. Kedua latar belakang penelitian dan PKM tersebut mendorong penulis untuk mencari peluang, apa dibalik upacara Babangkongan yang belum pernah ditulis secara khusus. Kemudian pada tahun 2020, penulis sendiri melakukan penelitian mandiri, sambil mencari peluang untuk bahan pengkajian baru. Akhirnya penulis memilih simbolisme katak (Bangkong=bahasa Sunda) dalam upacara Babangkongan. Adapun teori yang dipergunakan adalah teori mitos menurut pemikiran Mircea Eliade. Mitos merupakan realitas kultural yang kompleks karena itu sulit untuk memberikan batasan-batasan yang definitif terhadapnya. Eliade memandang mitos sebagai usaha manusia arkhais untuk melukiskan lintasan yang supra natural ke dalam dunia (Susanto, 1987, hlm. 71). Lintasan yang supra natural ke dalam dunia, dapat 
dicontohkan melalui upacara meminta hujan Babangkongan di Desa Surawangi Kecamatan Jatiwangi Kabupaten Majalengka.

\section{HASIL DAN PEMBAHASAN}

\section{Upacara Babangkongan}

Meskipun masyarakat Desa Surawangi mayoritas beragama Islam, namun keyakinan agama dapat dilatar belakangi pula oleh kepercayaan yang disebut autochthonous sebagaimana dinyatakan oleh James Georgas dan Kostas Mylonas: Cultures Are Like All Other Cultures, Like Some Other Cultures, Like No Other Culture (dalam Kim et all (ed), 2010, hlm. 323): autochthonous artinya lebih independen dari asal muasal yang diimpor, dan lebih terfokus pada isu-isu, adat istiadat, perilaku dan pelatihan lokal setempat. Babangkongan tertawarisi masyarakat Surawangi belum tercampuri dari asal muasal yang diimpor. Hubungannya dengan autochthonous, penulis berasumsi adanya "persamaan" dengan identitas otentik yang dikemukakan oleh Yasraf Amir Piliang (2009, hlm. 126) berdasarkan pendapat Robert D. Lee (1997) yaitu bahwa identitas otentik adalah identitas yang bukan konstruksi dan bentukan 'pihak lain', dengan standar-standar umum yang menjadi kebiasaan (habitus), common sense dan konvensi masyarakat di dalamnya. Pencarian identitas otentik, dalah pencarian pada 'akar' (root), 'asal usul atau 'dunia' di mana individu 'dilahirkan' yaitu pada keluarga, suku, bahasa, agama, ras, dan bangsa yang mendahului eksistensi individu. Identitas otentik ini diseluruh Kecamatan Jatiwangi, hanya Desa Surawangi yang memiliki upacara meminta Hujan, bernama Babangkongan.

Selanjutnya sebagaimana dinyatakan Catherina Bell dalam bukunya Ritual Theory, ritual practice (2009, hlm. 182) bahwa "Keyakinan agama telah dipahami dalam berbagai cara-seperti penjelasan pseudoscientific, rasionalisasi perilaku adat, ideologi pribadi atau komunal, atau doktrin yang sangat terstruktur formulasi yang isinya memiliki sedikit pengaruh pada perilaku." Kutipan tersebut membuka pemahaman tentang tumbuh dan berkembangnya keyakinan agama asli yang dipahami dalam berbagai cara, sebagaimana tradisi upacara Bababangkongan yaitu upacara meminta hujan di dalam masyarakat Desa Surawangi Kecamatan Jatiwangi Kabupaten Majalengka.

Sebelum sampai pada pembahasan tentang simbolismekatak, penulis memandang perlu mengutip penjelasan tentang simbolisme dari Mircea Iliade bahwa semua kegiatan manusia pada umumnya melibatkan simbolisme. Oleh karena itu manusia bukan hanya merupakan animal rationale, tetapi disebut juga homo simbolicum (Susanto, 1987, hlm. 61). Guna memperjelasnya, penulis memandang perlu mengutip definisi tentang simbolisme: "Simbolisme adalah penggunaan simbol untuk menandakan ide dan kualitas, dengan memberi mereka makna simbolis yang berbeda dari arti literalnya. Simbolisme dapat mengambil bentuk yang berbeda. Umumnya, itu adalah objek yang mewakili yang lain, untuk memberikan makna yang sama sekali berbeda yang jauh lebih dalam dan lebih signifikan. Namun, terkadang suatu tindakan, peristiwa, atau kata yang diucapkan 
oleh seseorang mungkin memiliki nilai simbolis. Misalnya, "senyum" adalah simbol persahabatan. Demikian pula, tindakan seseorang yang tersenyum kepada Anda dapat dianggap sebagai simbol perasaan kasih sayang yang dimiliki orang tersebut untuk Anda. https://literarydevices.net/symbolism/ (diunduh pkl 10.30 Wib. Tanggal 14 Juli 2020).

Setelah dipahami bahwa simbolisme merupakan penggunaan simbol, maka penulis memandang penting menjelaskan tentang simbol, sebagaimana dikatakan Dillistone (2002, hlm. 20):

"Sejauh menyangkut definisi kamus, rupanya ada kesepakatan umum bahwa sebuah simbol tidak berusaha untuk mengungkapkan keserupaan yang persis atau untuk mendokumentasikan suatu keadaan yang setepatnya. Malahan, fungsi simbol ialah merangsang daya imajinasi, dengan menggunakan sugesti, asosiasi, dan relasi. Barangkali deskripsi yang jelas yang saya temukan tentang fungsi simbol, yang sama sekali berlawanan dengan fungsi rumusanrumusan ilmiah yang tepat.."

Bertolak dari kutipan tersebut, bagi masyarakat Desa Surawangi sendiri pelaksanaan upacara Babangkongan tujuannya untuk mendatangkan hujan. Sebagaimana dikatakan oleh Suanda sebagai malim atau pawang Babangkongan (wawancara, Suanda, 24 Januari 2020): “Babangkongan telah dijalankan orang-orang Desa Surawangi sejak lama. Saya telah melakukannya sejak tahun 1950. Benar sekali, Babangkongan merupakan warisan dari karuhun (leluhur) yang diteruskan oleh generasi berikutnya. Pelaksanaannya spontan, terutama kalau dirasakan suasana alam yang seharusnya turun hujan tetapi hujan tidak turun turun disebut halodo. Maka kami segera melaksanakan upacara Babangkongan. Kalau tidak melaksanakan upacara Babangkongan hujan tidak akan turun. Manfaatnya nyata, karena setelah upacara dlaksanakan kirakira beberapa hari kemudian turun hujan walaupun tidak lebat."

Menggaris bawahi yang dikatakan Dillistone yang dikaitkan dengan perkataan Suanda sebagai Malim atau pawang Babangkongan, nampaknya tiga kata: sugesti, asosiasi, dan relasi menjadi memiliki kesinambungan dengan peristiwa upacara Babangkongan, di mana katak menjadi simbol yang dipilih secara turun temurun dan dipercaya memiliki kemanjuran (efficasy) bagi penduduk Desa Surawangi. Sugesti sebagai kekuatan daya hidup (levitational force) sangat berperan dan berpengaruh bagi para petani Desa Surawangi yang sawahnya ingin segera diguyur hujan. Hal tersebut juga asosiasi yang merupakan aktivitas mental yang menghubungkan satu hal atau ide atau tingkah laku dengan setiap hubungan yang dibentuk melalui proses belajar antar manusia dengan yang lainnya, juga merupakan gabungan berbagai peristiwa kejiwaan seperti antara kesan dan ingatan (Dagun, 2005, hlm. 74). Adanya proses belajar masyarakat dari satu generasi ke generasi berikutnya, juga adanya kesan dan ingatan yang tumbuh di bawah sadar masyarakat Desa Surawangi mendorong upacara Babangkongan senantiasa diselenggarakan, apabila keadaan alam yang seharusnya musim hujan menjadi halodo (hujan tidak turun-turun). Sementara relasi sangat terkait adanya hubungan timbal 


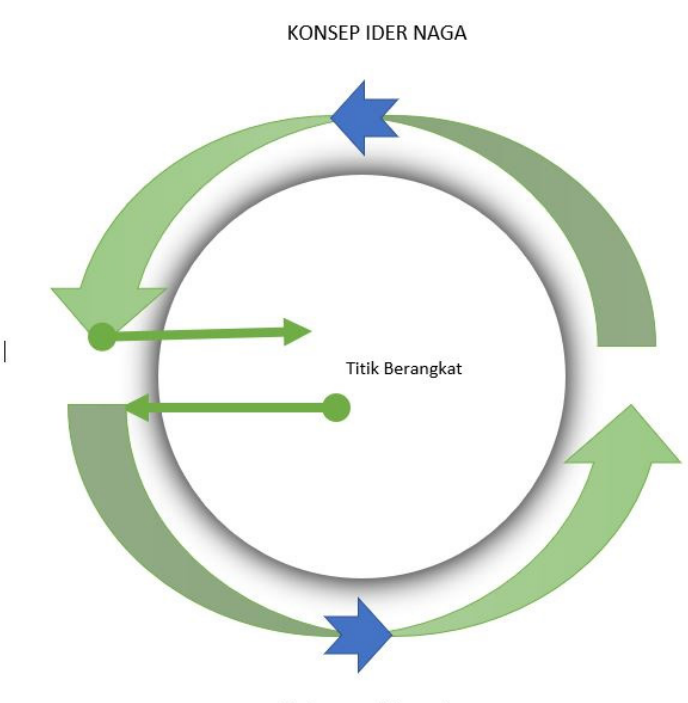

Melawan arah jarum jam

Gambar 1. Model konsep ider naga (melawan arah jarum jam) dalam Upacara meminta hujan Babangkongan

balik antara pelaku upacara Babangkongan dengan masyarakat Desa Surawangi yang rumahnya terlewati rombongan Babangkongan. Upacaranya sendiri bertolak dari rumah Kuwu (kepala desa), rombongan pelaku upacara bergerak meninggalkan titik pusat keberangkatan melingkari desa dengan konsep ider naga (melawan arah jarum jam, sebagaimana Tawaf dalam ibadah Haji). Berikut model konsep ider naga yang dipercaya masyarakat Desa Surawangi.

Konsep ider naga ini diwariskan secara turun temurun, mengapa melawan arah jarum jam? Melawan arah jarum jam, dapat dianggap sebagai waktu kudus. Sebagaimana dinyatakan oleh Mircea Eliade (Susanto, 1987, hlm. 53):

"Sebagaimana penghayatan mengenai ruang, manusia religius juga menghayati bahwa semua waktu itu tidak homogen, tidak sama kepadatan dan nilainya. Baginya, waktu dibedakan menjadi dua jenis, yaitu waktu profan dan waktu kudus. Waktu profan ialah waktu

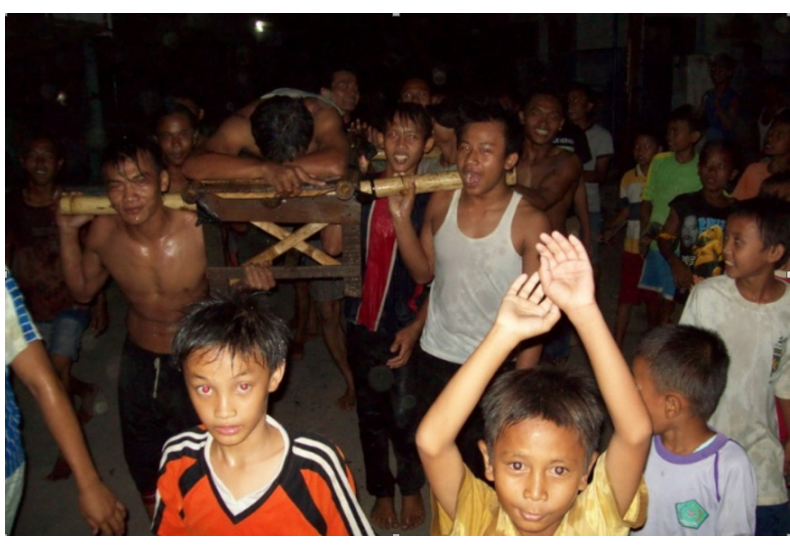

Gambar 2. Arak arakan dalam upacara meminta hujan Babangkongan di desa Surawangi Kecamatan Jatiwangi Kabupaten Majalengka (Sumber: Herfan Rusando, 2014)

biasa dalam kehidupan sehari-hari. Sedangkan waktu kudus ialah waktu yang diciptakan dan dikuduskan oleh para dewa, timbul pada zaman bahari, in ilo tempore, ab origine. Waktu kudus merupakan waktu yang diceritakan dalam mitos mitos, bukan bagian dari waktu historis kita, tetapi merupakan asal atau origo dari waktu kita ini. Perbedaan esensial antara waktu kudus dan waktu propan ialah, menurut kodratnya waktu kudus itu reversible, dapat balik. Waktu kudus merupakna waktu mitis yang selalu bisa dihadirkan kembali. Suatu kejadian sakral dari waktu lampau yang bersifat mitis itu dihadirkan kembali dalam tiap-tiap pesta religius. "

Babangkongan sebagai upacara meminta hujan untuk mendapatkan kemanjuran (efficacy) yang dipercaya oleh masyarakat desa Surawangi telah menjadi tradisi yang diwariskan secara turun temurun, dan dijaga kelangsungannya sampai hari ini. Tua muda, bahkan anak-anak melakukannya dengan meriah. Tradisi upacara Babangkongan dapat dianggap sebagai pesta religius atau pesta pora ritual sebagaimana dinyatakan kembali oleh Mircea Eliade (Susanto, 1987, hlm. 59): 
"Pesta pora ritual macam ini juga dilakukan untuk kesuburan tanah dan kepentingan panen. Dengan penghapusan norma, batas dan individualitas, manusia mencapai keadaan benih-benih yang melebur di dalam tanah, kehilangan bentuknya untuk melahirkan tumbuh-tumbuhan baru. Dalam pesta pora itu itu manusia juga berharap-lewat pengidentifikaian dirinya dengan keadaan tanpa bentuk dan eksistensi pra kosmis-agar dia diperbaharui dan dilahirkan kembali menjadi seorang manusia baru."

Pesta pora ritual sebagaimana dinyatakan Mircea Eliade, bagi masyarakat Desa Surawangi membuka pemahaman baru sebagai "manusia baru" artinya memiliki kesadaran baru bahwa leluhur mereka telah memberikan warisan (walaupun pada awalnya telah dilupakan) namun beruntung masih ada "daya ingat yang pernah mengalaminya" sebagaimana halnya yang dialami Yuyum sewaktu kecil, dan Subana sewaktu muda. Leluhur desa mewariskan upacara meminta hujan Babangkongan sampai sekarang, apalagi setelah dilakukan proses penyadaran baru sebagai "manusia baru" yaitu manusia yang sadar pada dunia pariwisata. Babangkongan sesungguhnya berpeluang besar dijadikan seni kemas (package art) untuk kebutuhan dunia pariwisata daerah. Maka program PKM (Pengabdian Kepada Masyarakat) tahun 2019 dilakukan oleh Yayat Hidayat dan penulis sendiri. Hasilnya merupakan kerjasama kreatif bersama masyarakat desa, terutama ibu-ibu dan anak-anak desa. Bentuknya

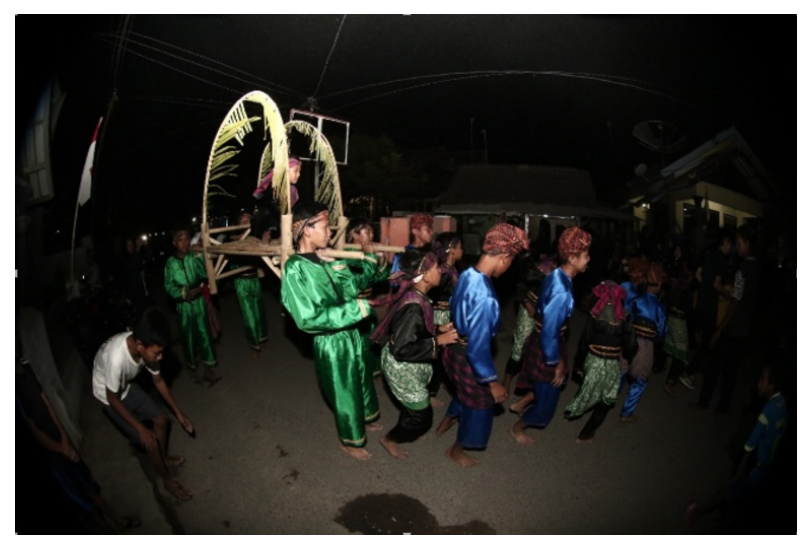

Gambar 3. Contoh Helaran Babangkongan sebagai seni kemasan (package art) yang dilakukan anak-anak Desa Surawangi (Sumber: Herfan Rusando, 2019)

pengemasan upacara Babangkongan menjadi bentuk pertunjukan Helaran (arak-arakan). Sebagaimana dinyatakan Yayat Hidayat (2019, hlm. 13): proses garap seni tidak lepas dari pengalaman penciptanya, baik itu dari cerita, atau melihat sesuatu. Pengalaman terjadi dari pengamatan objek dan dipahami tentang apa yang diamati kemudian dijadikan sebagai objek penciptaan.

Di samping itu pengamatan terhadap lingkungan dilakukan, terutama pesawahan yang terdapat di sekitar desa Surawangi. Sawah bagi masyarakat Surawangi menjadi sumber kehidupan petani yang paling utama. Sawah, sebagaimana dinyatakan Suhardji S (2011, hlm. 308): Sawah adalah tempat bercocok tanam padi yg banyak memerlukan pengairan. Sawah dikenal tanah tadah hujan atau lahan kering dan tanah basah. Swah tidak terdapat diperkotaan. Sawah hanya terdapat di pedesaan. Bagi masyarakat des Surawangi sawah memang sumber kehidupan, maka ketika terjadi halodo (hujan tidak turunturun) mereka mengingat tradisi leluhurnya, yaitu mengadakan upacara meminta hujan Babangkongan. 
Posisi Katak yang ditandu, menjadi simbol khas dari seni kemas Babangkongan. Simbol Katak tidak dihilangkan, tetapi diutamakan karena daya tariknya. Di mana anak-anak pengiring meniru suara katak berbunyi kung-kong-kung-kong secara bersahutan, dan pertunjukan pun menjadi meriah.

\section{Babangkongan yang diwariskan}

Perkembangan upacara meminta hujan Babangkongan ini pada kenyataannya memiliki dua bentuk, pertama adalah bentuk upacara meminta hujan Babangkongan yang asli, kedua adalah upacara Babangkongan hasil kreasi. Berikut gambaran Babangkongan Desa Surawangi yang diwariskan, di mana waktu kudus dan waktu propan beririsan. Waktu kudus yaitu waktu yang diplih berdasarkan kesepakatan bersama untuk melaksanakan Upacara meminta hujan Babangkongan. Sedangkan waktu propan bisa dilaksanakan kapan saja sesuai kebutuhan dunia pariwisata, sebagaimana seni kemas Babangkongan yang sudah dimiliki pula. Namun keduanya memiliki proyeksi terhadap kesuburan, kesuburan dapat dikaitkan dengan panen yang berhasil karena upacara Babangkongan yang asli dan juga pendapatan tambahan karena upacara Babangkongan kreasi. Keduanya tetap mendudukan Bangkong (Katak) sebagai simbol sentral yang ikonik.

\section{Simbolisme katak}

Mengapa katak? Katak atau Bangkong (bahasa Sunda) merupakan binatang yang akrab dengan lingkungan kehidupan manusia, binatang ini sangat dikenal sejak lama di

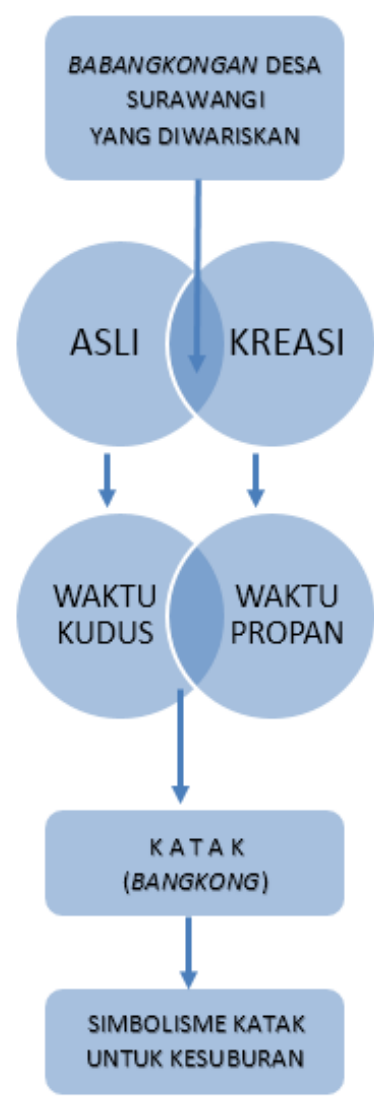

Gambar 4. Bagan Babangkongan yang diwariskan di desa Surawangi

dalam peradaban-peradaban kuno. Baik itu pada suku suku asli Afrika, Amerika Latin, maupun pada bangsa Cina, Jepang, India dan yang lainnya. Demikian pula halnya dalam AlQuran(Q.SAl-Araaf Ayat:133):Katakadalah hewan yang disebutkan oleh Allah dalam surat Al A'raaf ayat 133. Dalam ayat ini, Allah menceritakan azab yang diturunkan kepada Fir'aun dan pengikutnya yang kafir. Allah mengirimkan ribuan katak untuk mengazab mereka. "Maka Kami kirimkan kepada mereka topan, belalang, kutu, katak dan darah sebagai bukti yang jelas, tetapi mereka tetap menyombongkan diri dan mereka adalah kaum yang berdosa". Terdapat keterangan lain, bahwa katak memiliki hubungan dengan ekosistem sawah. Dalam ilmu ekosistem katak digolongkan sebagai ekosistem sawah, karena 
katak lebih banyak ditemukan di sawah, dan akan lebih mudah apabila dijelaskan dengan mengunakan ekosistem sawah. Dalam ilmu ekosistem terdapat berbagai sub bab antara lain ialah rantai makanan, Katak dalam rantai makanan berperan sebagai konsumen tingkat II yang berfungsi untuk memangsa konsumen I. Dari rantai makanan tersebut dapat diketahui katak merupakan konsumen kedua yang bertugas untuk memangsa serangga yang memakan padi. Apabila disambungkan dengan hadis larangan membunuh katak dan keseimbangan alam semesta (kosmos) maka memang katak tidak boleh dibunuh, karena apabila dibunuh akan merugikan petani yang menanam padi, serangga akan menyebar secara pesat karena serangga bisa secara maksimal mengkonsumsi padi tanpa ada yang memangsa dan ular akan menjadi kelaparan dan menganggu petani. (gomuslim. co.id, diunduh 8 Juli 2021, pkl 7.30 WIB)

Katak memiliki 12 genus di dunia, disebut Genus Rana (http://sysbio.oxfordjournal by guest Juli 21, 216. Diunduh 3 Juli 2021). Di manakah katak dapat ditemukan dalam kebudayaan lama? Salah satu contohnya terdapat dalam Nekara perunggu zaman pra sejarah di Nusantara. Nekara merupakan semacam berumbung yang dibuat dari perunggu, dibagian tengah berpinggang dan pada sisi atasnya tertutup. Pada masa prasejarah, Nekara dianggap sebagai benda suci. Nekara digunakan pada waktu upacara penting saja, misalnya untuk memanggil hujan, memanggil arwah nenek moyang dan dipakai sebagai genderang. Berikut Katak pada sebuah perunggu zaman pra sejarah. Ada hubungannya dengan ilmu sihir hujan. Berasal dari Bima (Van Der Hoop, 1949,

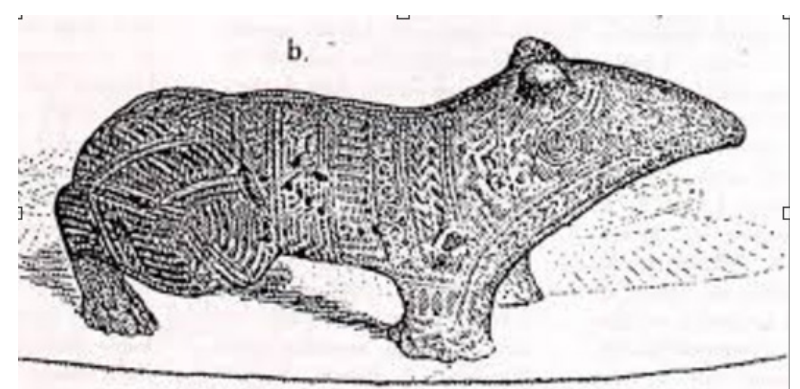

Gambar 5. Patung Katak dari Nekara berasal dari Bima, dalam buku ragam Perhiasan Indonesia (Sumber: Van der Hoop,1949, hlm. 219).

hlm. 219).

Katak merupakan binatang di dua alam (amphibi), yang dianggap memiliki hubungan supranatural dengan lingkungan. Sebagaimana dinyatakan (Friedle dan Klump 2002, Gasser et al. 2009) dalam Kirono (2015, hlm. 269). Katak juga memiliki suara struktur spektral dan beberapa struktur temporal suara katak yang umumnya berhubungan dengan karakteristik fisik seekor katak berpotensi untuk sebagai perangkat yang menggambarkan identitas jenisnya. Spektral (berkenaan dengan getaran-getaran) dan temporal (berkenaan dengan waktu waktu tertentu), mirip dengan suara katak yang ditiru oleh para pelaku upacara meminta hujan Babangkongan, bersahut-sahutan, membangun "musikalitas" yang meriah, yang mudah di dengar oleh penduduk yang rumahnya dilewati pelaku Babangkongan dan segera menyiapkan saweran (memberi uang) dan air guyuran dalam ember, untuk mengguyur aktor yang berberan sebagai Katak yang diusung dalam arak-arakan malam itu. Katak dan hujan memiliki relasi kuat dalam konteks kesuburan, karena itu masuk akal kalau masyarakat agraris, para 
petani mendudukan binatang katak menjadi bagian dari kehidupan mereka. Sebagaimana halnya dengan masyarakat Desa Surawangi. Desa yang memiliki pesawahan cukup luas dan subur. Desa Surawangi merupakan salah satu desa di Kecamatan Jatiwangi Kabupaten Majalengka yang penduduknya mayoritas bermata pencaharian sebagai petani dan buruh. Para petani sangat tergantung dari sawah yang dimilikinya, karena itu mereka merasa perlu melakukan upacara Babangkongan, kalau hujan tidak turun turun. (Wawancara, Yuyum Sri Rumsari, 2020), Yuyum seorang mantan Kuwu (sebutan lokal kepala desa) wanita yang sangat peduli pada keinginan masyarakat Desanya. Maka ketika berlangsung hujan tidak turun-turun, memanggil kokolot (orang yang dituakan) yaitu Suanda (81 tahun) yang dikenal sebagai seorang Malim atau Pawang yang dipercaya memiliki kemampuan untuk memimpin upacara meminta hujan Babangkongan. Baik Yuyum maupun Suanda dan juga masyarakat Desa Surawangi percaya, bahwa dengan upacara meminta hujan Babangkongan hujan akan turun. Anggapan Yuyum dan Suanda juga masyarakat Surawangi, dapat dikaitkan dengan pernyataan J.E. Cirlot dalam bukunya A Dictinory of Symbols (1971, hlm. 344): Kodok Aspek terbalik dan infernal dari simbol katak; artinya, signifikansi simbolis adalah sama meskipun dalam arti negatif. Atau, seperti yang dikatakan oleh bahasa tradisional pemikiran esoteris: 'Ada juga hewan-hewan tertentu yang misinya adalah memecah cahaya astral dengan proses penyerapan yang khas bagi mereka. Ada sesuatu yang menarik tentang tatapan mereka: mereka adalah katak

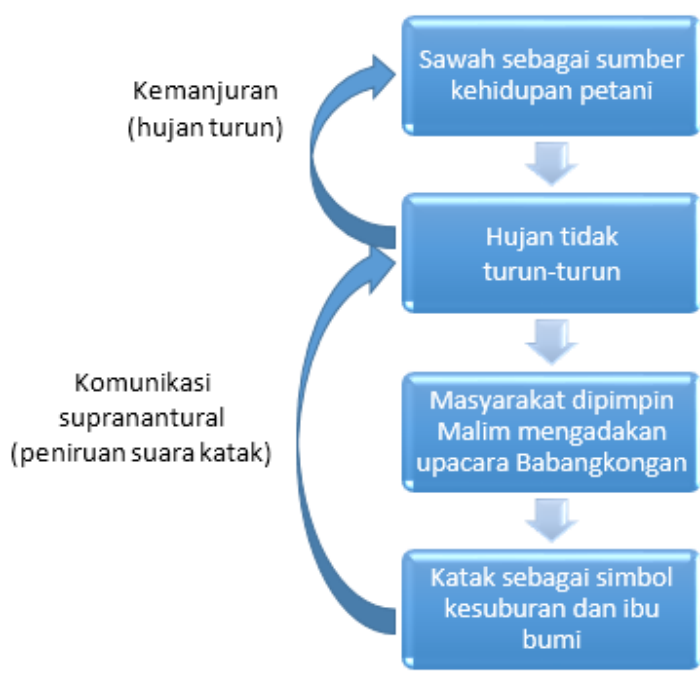

Gambar 6. Model Alur Efficacy (kemanjuran) Upacara Meminta Hujan Babangkongan.

dan basilisk (reptil yang dimitoskan) (1971, hlm. 344). Kemanjuran upacara meminta hujan Babangkongan, telah dibuktikan, ketika tahun 2014 pasca upacara, tak lama kemudian turun hujan di sekitar Desa Surawangi, meskipun hujan itu tidak lebat. Tetapi itulah wujud kemanjuran dari upacara meminta hujan Babangkongan di Desa Surawangi Kecamatan Jatiwangi Kabupaten Majalengka. Berikut model alur efficacy (kemanjuran) dari Upacara meminta hujan Babangkongan kaitannya dengan Bangkong (Katak) sebagai simbol kesuburan dan ibu bumi.

\section{SIMPULAN}

Upacara meminta hujan Babangkongan yang dilakukan masyarakat Desa Surawangi Kecamatan Jatiwangi Kabupaten Majalengka telah berlangsung lama, dan menjadi tradisi yang diwarisakan secara turun temurun. Upacara Babangkongan ini dipimpin oleh seorang malim atau pawang yang memiliki kemampuan supranatural untuk memimpin 
sebuah upacara sakral, karena dilaksanakan pada waktu kudus (waktu yang disucikan) yakni malam hari sampai tengah malam. Upacara Babangkongan dlaksanakan dengan prosesi arak-arakan mengelilingi desa dengan konsep ider naga, yakni melawan arah jarum jam, sebagaimana di dalam ibadah Tawaf dalam Haji pada umat Islam sewaktu berhaji.

Upacara meminta hujan Babangkongan ini memperlihatkan pengarakan aktor (pemain yang berperan sebagai bangkong (bahasa Sunda) atau katak, dengan cara diusung di atas tandu terbuka, duduk dan tengkurap meniru prilaku katak sepanjang upacara berlangsung. Di samping itu juga para pengusung yang terdiri dari tua muda ikut serta mengarak keliling desa, secara spontan menirukan suara bangkong yang bersahut-sahutan, berirama, naik turun, dalam musikalitas yang meriah, baik secara spektral maupun temporal. Anggota masyarakat yang dilewati arak-arakan pun telah menyiapkan saweran dan ember berisi air, di mana ketika arak-arakan melewatinya, segera menyiram air kepada aktor bangkong, serta memberikan saweran dengan uang seadanya.

Upacara Babangkongan menjadikan Bangkong (Katak dalam bahasa Sunda) sebagai titik perhatian dan daya tarik, sekaligus juga simbolisme dari adanya hubungan komunikasi supranatural yang dipercaya memiliki kemanjuran (efficacy) bagi turunnya hujan setelah upacara meminta hujan dilaksanakan. Bangkong dianggap memiliki simbol kesuburan (vertility) dan ibu bumi (mother earth) bagi masyarakat yang mempercayainya karena dapat medatangkan hujan.

\section{DAFTAR PUSTAKA}

Bell, Catherine. (2009). Ritual theory, Ritual Practice, New York: Oxford University Press.

Cirlot, J.E. (1971). A Dictinory of Symbols, Second Edition, translate from the Spanish by Jack Sage, London: Rouledge.

Creswell, Jhon W. (2012). Research Design: Pendekatan Kualitatif, Kuantitatif, dan Mixed. Diterjemahkan oleh. Ahmad Fawaid, Edisi ketiga, Cetakan ke II, Yogyakarta: Pustaka Pelajar.

Dagun, Save M. (2005). Kamus Besar Ilmu Pengetahuan, Cetakan keempat, Jakarta: Lembaga Pengkajian Kebudayaan Nusantara (LPKN).

Dillistone, FW. (2002). The Power of Symbol, Yogyakarta: Hanindita.

Hefni Moch. (2008). "Bernegosiasi" dengan Tuhan melalui Ritual Dhâmong, (Studi atas Tradisi Dhâmmong sebagai Ritual Permohonan Hujan di Madura, Jurnal KARSA, Volume XXIII. No 1, April.

Hidayat, Lina Marliana. (2016). Cingcowong: Upacara ritual meminta hujan di desa Luragung Landeuh Kecamatan Luragung Kabupaten Kuningan, Ekspresi SENI, Volume 17, No 2, November, ISSN: 1412-1662. (230-243)

Hidayat, Yayat, Lina Marliana Hidayat. (2019). Pengemasan Upacara Babangkongan menjadi bentuk Pertunjukan Helaran, Makalangan, Volume 6, Nomor 2. Edisi Desember. (9-16).

Kim, Uichol, Khuo Shu Yang, Kwang Kuo Hwang (ed), (2010). Indigenous and Cultural Psychologi: memahami orang dalam konteksnya, Terjemahan: Helly Prajitno Soetjipto, Sri Mulyantini Soetjipto.Yogyakarta: Pustaka Pelajar

Kirono, Sasi, Mirza D. Kusrini, Yeni A. Mulyani,(2015). Album suara (Refertoire) katak Serasah Lebtrobachium hasseltii 
Tschudi, 1883 in Situ Gunung, Media Konservasi, Vol 20. No 3, Desember. (269-276)

Piliang, Yasraf Amir. (2009). Membangun Identitas: Meretas Perangkap Budaya Populer dan Konsumerisme, Panggung, Vol 19, 2 April-juni, ISSN 084-3429. (118-129)

S, Suharji. (2011). Tayub Jangrungan sebagai Sarana Upacara Lempokan Nyiwer Sawah, Panggung, Vol 21 No3, Juli-September. ISSN: 08543429. (306-318)

Susanto, Hary P.S. (1987). Mitos: Menurut Pemikiran Mircea Eliade, Yogyakarta: Penerbit Kanisius.

Van Der Hoop, A.N.J.Th.a.Th. (1949). Indonesiche Siermotivien:Ragam Perhiasan Indonesia, Indonesian Ornamental Design, Koninklijk Bataviaasch Genootscap Van Kunsten En Wetenschappen.

\section{Sumber internet}

https://iterarydevices.net/symbolism/ (diunduh pkl 10.30 Wib. Tanggal 14 Juli 2020).

https://www.gomuslim.co.id/read/ khazanah/2019/10/13/15228/-p-kataktermaktub-dalam-alquran-sebagaibinatang-yang-haram-dibunuh-p-. html (diunduh 10 Juli 2020-7.30)

\section{Narasumber}

Yuyum Sri Rumsari (63 tahun), mantan Kuwu (Kepala Desa Surawangi). Wawancara, 24 Januari 2020.

Suanda (80), Malim atau Pawang Babangkongan. Wawancara, 24 Januari 2020. 